\title{
MULTI-JUNCTION THERMOCOUPLE ARRAY FOR IN-SITU TEMPERATURE MONITORING OF SOFC: SIMULATION
}

\author{
Manoj Ranaweera ${ }^{1}$, Indae Choi ${ }^{2}$, Jung-Sik $\mathrm{Kim}^{3}$ \\ ${ }^{1,2,3}$ PhD Student, Dept. of Aeronautical \& Automotive Eng., Loughborough University, LE11 3TU, United Kingdom
}

\begin{abstract}
Novel multi-junction thermocouple architecture was developed and simulated to in-situ monitor the temperature distribution over a Solid Oxide Fuel Cell (SOFC). This thermocouple architecture requires only $\{N+1\}$ number of wires for $N$ number of independent temperature measuring points. Therefore, $N+1$ architecture can independently measure temperature at multiple points simultaneously with much less number of wires than a set of thermocouples require for the same number of independent temperature measurements. Requiring less number of external wires is a distinct advantage, particularly, in constrained environments such as those within SOFC stacks. A thermocouple array having 4 independent temperature measuring points with 5 thermo-elements was simulated in MATLAB. Alumel (Ni:Al:Mn:Si-95:2:2:1 wt) and Chromel (Ni:Cr-90:10 wt) were chosen as thermo-element materials because of their wide applicability in the industry as $K$-type thermocouples. The junctions were considered to be spot welded. Three sets of simulations were performed to investigate two aspects: validation of the multi-junction thermocouple concept and investigation of the effect of the heat affected zone created in spot welding to the temperature measurement. Simulation code generates random temperature values for each junction within a pre-defined range. Temperatures at the boundaries of heat affected zones were also generated randomly according to a pre-defined criterion. The change of Seebeck coefficients within the heat affected zone was set as a percentage change of their corresponding materials Seebeck coefficient. The temperature gradient induced emf values for each sensing point were calculated from Seebeck coefficients. The calculated emf was then mapped back to temperature using ASTM approved inverse conversion function. These mapped temperatures were then compared with the set temperatures for each junction and they were in very good agreement.
\end{abstract}

Keywords: SOFC, Temperature Measurements, Thermocouple

\section{INTRODUCTION}

Thermal cycling at high temperature (usually in the range from $600^{\circ} \mathrm{C}-900^{\circ} \mathrm{C}$ ) and uneven temperature distribution in SOFC leads to severe mechanical failures such as, delamination and cracking of cell components, promoting premature degradation. Attempts were made to model and predict such failures based on estimated temperature distribution over cell ${ }^{[1-4]}$. To mitigate such phenomena as well as to obtain better understandings of the stack performance, it is required to monitor the actual temperature distribution over the cell and stack while they are in operation at temperature. Further, the knowledge on actual temperature distribution enables to understand degradation mechanisms and the modelling based control of SOFC systems.

Present efforts on understanding temperature distribution over cell and stack are mainly confined to simulations. In which, application of physical modelling ${ }^{[5-13]}$ as well as Artificial Neural Network modelling (ANN) ${ }^{[14-17]}$ could be noted. Physical models rely on various assumptions and simplification of conditions which do not necessarily exist in real operation. Further, changes in operating conditions such as current, flow rate, etc. induces detrimental evolutions in the temperature profile ${ }^{[18]}$, which may not be predictable with steady state physical models. Therefore, these models need validation with experimental results. On the other hand, the accuracy of training data is central to the accuracy of predicted data of ANN. Hence, it is essential to have experimental temperature measurements.

Attempts made on measuring temperature distribution on SOFC are limited in literature compared to simulations. Morel et al ${ }^{[19]}$ used electrochemical impedance spectroscopy (EIS) to in-situ evaluate the temperature gradient along a cell. However, this method cannot measure localised temperature. In a study by Saunders and Davy ${ }^{[20]}$ to investigate the steam-methane reforming process within direct internal reforming SOFC (DIR_SOFC), a commercial IR thermometer (Omega Vanzetti Model No. 1562) was used to measure point temperature at $10 \mathrm{~mm}$ separation on the anode along the centre line of $100 \mathrm{~mm}$ x $50 \mathrm{~mm}$ cell. The cell was placed inside an oven having a transparent window to make the cell visible to thermometer. However, this approach is not feasible with multi-cell stacks. Contact thermometry appears more promising than non-contact thermometry in in-situ monitoring cell/ stack temperature. Razbani et al ${ }^{[15][21]}$ inserted 5 K-type thermocouples $(\phi$ $0.5 \mathrm{~mm})$ inside the middle cell of a 5 -cell $(110 \mathrm{~mm} \times 86 \mathrm{~mm})$ short stack to measure the temperature at the four corners and one from the middle. Further, they state that researchers at Jülich $\mathrm{GmbH}$ were able to measure the temperature profile of a $5 \mathrm{~kW}$ SOFC stack by inserting 36 thermocouples. Guan et al. ${ }^{[22]}$ and Bedogni et al ${ }^{[23]}$ have also used the method of inserting thermocouples to measure gas flow temperature at inlet and outlet of a stack. It is evident that thermocouples are much popular in the task. In fact, 
thermocouple is a robust sensor for harsh environment temperature measurements. However, inserting thermocouples inside a fuel cell stack via the previously applied methods, either simply put commercial thermocouples through gas channels or draw holes to put them, may significantly disturb the normal operation of the stack causing the output being deteriorated from its normal operation. Further, inserting a large number of sensors inside the stack to measure temperature with greater spatial resolution is problematic due to the difficulties in embedding a large number of wires within the assembled systems; in addition, this will worsen the level of disturbance. Moreover, thermocouple freely hanging in a stack does not measure the exact cell surface temperature. Due to these multifaceted reasons, necessity of a technology, which is capable of measuring the cell temperature with greater spatial resolution and causing only a minimum disturbance to normal stack operation is evident. This study is to develop a technology that can be applied to commercial SOFCs and used to help build an accurate, realtime three-dimensional temperature map of a SOFC stack while delivering minimum disturbance to its normal operation and output.

\section{DESIGN AND METHODOLOGY}

$N+1$ architecture with 4 independent sensing points and 5 thermo-elements $(N=4)$, shown in Fig 1 , was virtually constructed and simulated in MATLAB. Four temperature measuring points are denoted by $J_{1}$ to $J_{4}$. Each of these points is formed by intersecting two dissimilar thermoelement materials. Thermo-element $a-b$ is made of Chromel and each of thermo-elements $c-d, e-f, g-h$, and $i$-j are made of Alumel.

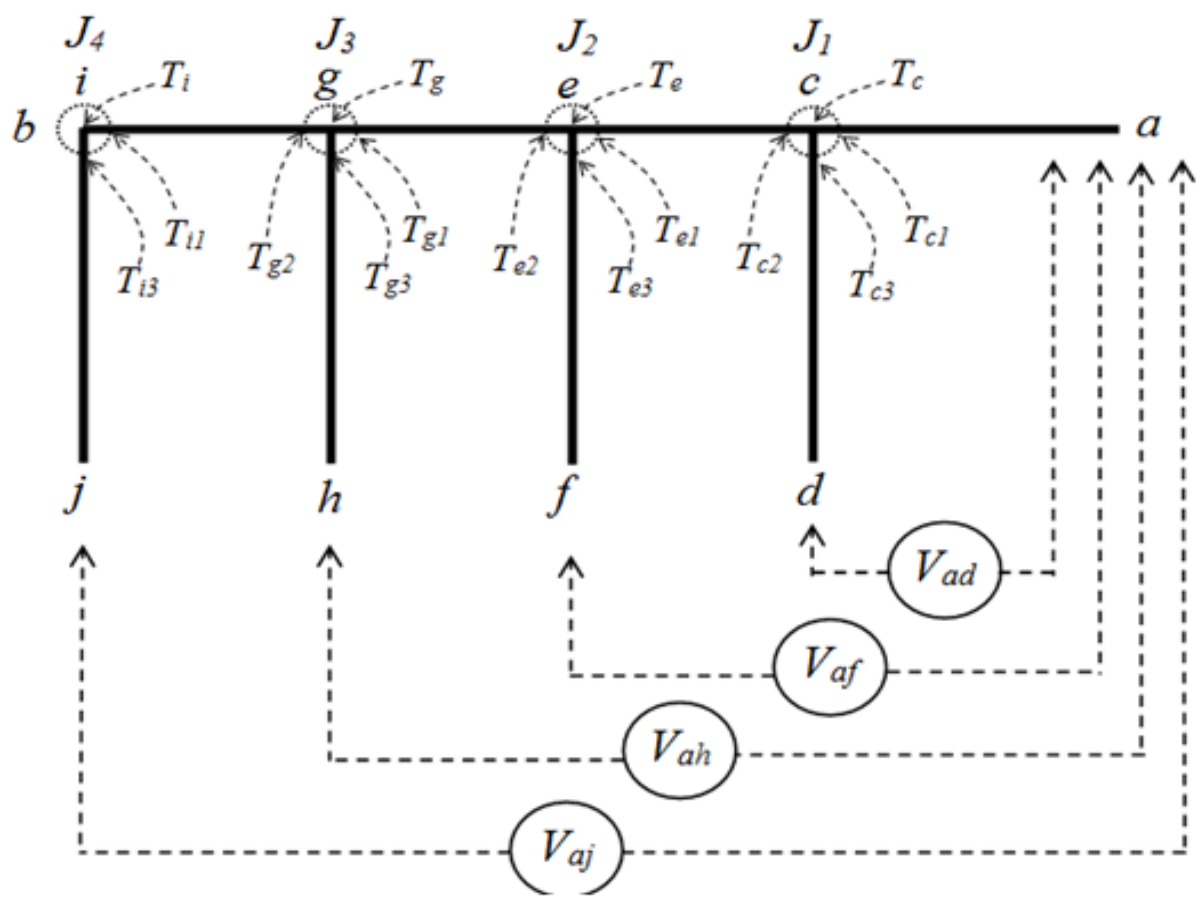

Fig 1: Sensor array layout

The sensor array is considered to be made by spot welding of thermo-elements at each junction. The sections enclosed in dotted circle represent the heat affected zone (HAZ) of spot welding. The points of intersection between circle and individual thermo-elements define the boundary of HAZ on corresponding thermo-elements.

Temperatures at junctions $\mathrm{J}_{1}$ to $\mathrm{J}_{4}$ are denoted by $\mathrm{T}_{\mathrm{c}}, \mathrm{T}_{\mathrm{e}}, \mathrm{T}_{\mathrm{g}}$, and $T_{i}$ respectively. The temperatures denoted by a numbered subscripts represent the temperature at the boundary of HAZ on corresponding thermo-element; for example, $\mathrm{T}_{\mathrm{c} 1}, \mathrm{~T}_{\mathrm{c} 3}, \mathrm{~T}_{\mathrm{e} 3}$ are the temperatures at the HAZ boundary of thermo-element $a-c, c-d$, and the $e-f$ respectively. Each thermo-element, $c-e, e-g$, and $i-g$, have two HAZ boundaries at their both ends. Since Seebeck coefficient of materials depend on the micro-structure, there is a possible influence from HAZ to the Seebeck coefficient. Hence, the HAZ is distinguished from the rest of the sections in this simulation to investigate the influence of $\mathrm{HAZ}$ to the performance.

Thermo-electric emf, $\mathrm{V}_{a d}, \mathrm{~V}_{a f}, \mathrm{~V}_{a h}$, and $\mathrm{V}_{a j}$ are a measure of the temperature at junction $J_{1}$ to $J_{4}$ respectively. These values were calculated using following standard equations. In which, $S_{\mathrm{cr}}$ and $\mathrm{S}_{\mathrm{al}}$ represent the Seebeck coefficients of Chromel and Alumel respectively whereas $S_{\text {al }}^{\prime}$ and $S_{\text {cr }}^{\prime}$ represent the Seebeck coefficients in HAZ of Alumel and Chromel respectively. 


$$
\begin{aligned}
& V_{a d}=\int_{T_{0}}^{T_{c 1}} S_{a l} d T+\int_{T_{c 1}}^{T_{c}} S_{a l}^{d} d T+\int_{T_{c}}^{T_{c s}} S_{c y}^{d} d T+\int_{T_{c 3}}^{T_{0}} S_{c r} T \\
& V_{a f}=\int_{T_{0}}^{T_{c 1}} S_{a l} d T+\int_{T_{c 1}}^{T_{c 2}} S_{a l}^{d} d T+\int_{T_{c 2}}^{T_{a 1}} S_{a l} d T+\int_{T_{a 1}}^{T_{a}} S_{a l}^{d} d T+\int_{T_{a}}^{T_{a 3}} S_{c y}^{d} d T+\int_{T_{a 3}}^{T_{0}} S_{c r} T \\
& V_{a h}=\int_{T_{0}}^{T_{c 1}} S_{a l} d T+\int_{T_{c 1}}^{T_{c 2}} S_{a l}^{d} d T+\int_{T_{c 2}}^{T_{a 1}} S_{a l} d T+\int_{T_{a 1}}^{T_{a 2}} S_{a l}^{d} d T+\int_{T_{a 2}}^{T_{g 1}} S_{a l} d T+\int_{T_{g 1}}^{T_{g}} S_{a l}^{d} d T+\int_{T_{g}}^{T_{g 3}} S_{c y}^{d} d T+\int_{T_{g 3}}^{T_{00}} S_{c y} T \\
& V_{a j}=\int_{T_{0}}^{T_{c 1}} S_{a l} d T+\int_{T_{c 1}}^{T_{c 2}} S_{a l}^{d} d T+\int_{T_{c 2}}^{T_{a 1}} S_{a l} d T+\int_{T_{a 1}}^{T_{a 2}} S_{a l}^{d} d T+\int_{T_{a 2}}^{T_{g 1}} S_{a l} d T+\int_{T_{g 1}}^{T_{g 2}} S_{a l}^{d} d T+\int_{T_{g 2}}^{T_{i 1}} S_{a l} d T+\int_{T_{i 1}}^{T_{i 1}} S_{a l}^{d} d T \\
& +\int_{T_{i}}^{T_{i 3}} S_{c y}^{d} d T+\int_{T_{i 3}}^{T_{0}} S_{c r} T
\end{aligned}
$$

The Seebeck coefficients shown in Table 1 were taken as the boundary values and those at other temperatures were estimated by two methods: piecewise liner interpolation and liner regression. Figure 2 shows the emf estimated by using Seebeck coefficients obtained by above two methods and the ITS-90 standard emf value for the temperature range $0^{\circ} \mathrm{C}$ to $1000^{\circ} \mathrm{C}$. It can be seen that Seebeck coefficients generated by liner regression induces emf that is much closer to ITS-90 emf values. Therefore, liner regression was used to estimate the Seebeck coefficients.

Temperature at each junction can be set to vary randomly within a pre-defined range. The change of Seebeck coefficient in HAZ for each material can be set as a percentage variation of the corresponding un-affected material's Seebeck coefficient. The temperature at the boundary of each HAZ can also be set to vary randomly within a pre-defined range. The range is defined as a percentage of the corresponding junction temperature. By using these features added to the simulation, the multijunction thermocouple array design was evaluated and the influence of HAZ to the accuracy of temperature measurement was investigated.

Table 1: Seebeck Coefficients ${ }^{[24]}$

\begin{tabular}{|l|l|l|}
\hline \multirow{2}{*}{$\begin{array}{l}\text { Temperature } \\
\left({ }^{0} \mathrm{C}\right)\end{array}$} & \multicolumn{3}{|l|}{ Seebeck Coefficient $\left(\mu \mathrm{V} /{ }^{0} \mathrm{C}\right)$} \\
\cline { 2 - 3 } & Alumel & Chromel \\
\hline 0 & -17.7 & 21.8 \\
\hline 200 & -16.2 & 23.7 \\
\hline 400 & -20.0 & 22.2 \\
\hline 600 & -24.0 & 18.5 \\
\hline 800 & -27.2 & 13.8 \\
\hline 1000 & -29.6 & 9.4 \\
\hline
\end{tabular}

\section{RESULTS AND DISCUSSION}

There were 3 sets of simulations carried out. Number of iterations per each simulation was set to 50 to ease the visual analysis of graphs: too large iterations makes the graphs unclear due to large number of data points and too less number of iterations makes the simulation less general. Temperature gradient induced emf values for junctions were estimated in all iterations. The temperature corresponding to this estimated emf was then calculated using the thermocouple inverse function given below where $t_{90}$ is the temperature in ITS-90 scale and $\mathrm{d}_{0}$ to $\mathrm{d}_{9}$ are constants, and $\mathrm{E}$ is the emf. This calculated temperature and the randomly generated temperature were plotted against iteration number for all 4 junctions for comparison.

$$
\mathrm{t}_{90}=\sum_{k=0}^{9} d_{k} E^{k}
$$

Simulation 1: Validation of the multi-junction array concept.

The junction temperature was set to randomly vary within the range from $900^{\circ} \mathrm{C}$ to $1000^{\circ} \mathrm{C}$. This range was chosen because, the expected maximum operating temperature of SOFC lies within this range. Any changes to Seebeck coefficient within the HAZ are neglected. Figure 3 shows the actual and estimated temperature for 50 iterations. Even without any influence from HAZ, a noticeable difference between actual and estimated temperature can be noted.

The estimated temperature entirely depends on the estimated Seebeck coefficients at each temperature and Figure 2 shows that the estimated emf, hence the estimated Seebeck coefficient, is not very accurate in the temperature range from $900^{\circ} \mathrm{C}$ to $1000^{\circ} \mathrm{C}$. The Seebeck coefficient estimation is relatively accurate in the range from $200^{\circ} \mathrm{C}$ to $300^{\circ} \mathrm{C}$. 
Hence, the simulation as repeated for this range and the junction thermocouple array could measure the temperature output is shown in Fig 4. Within this range, the estimated temperatures very satisfactorily agree with their corresponding actual temperatures. Therefore, the multi-

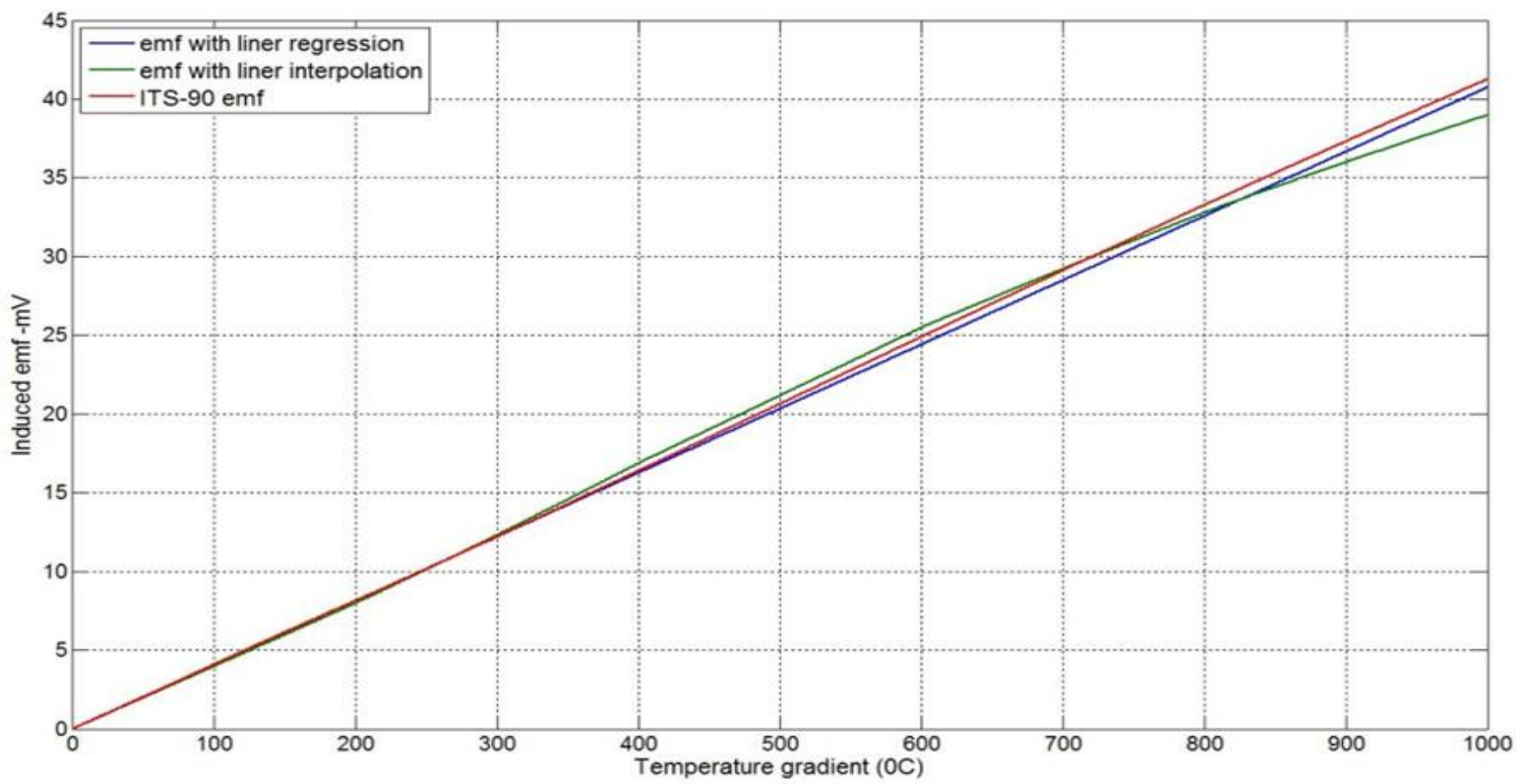

Fig 2: Comparison of emf generated under Seebeck coeffecients obtained from liner interpolation and liner regression with ITS$90 \mathrm{emf}$
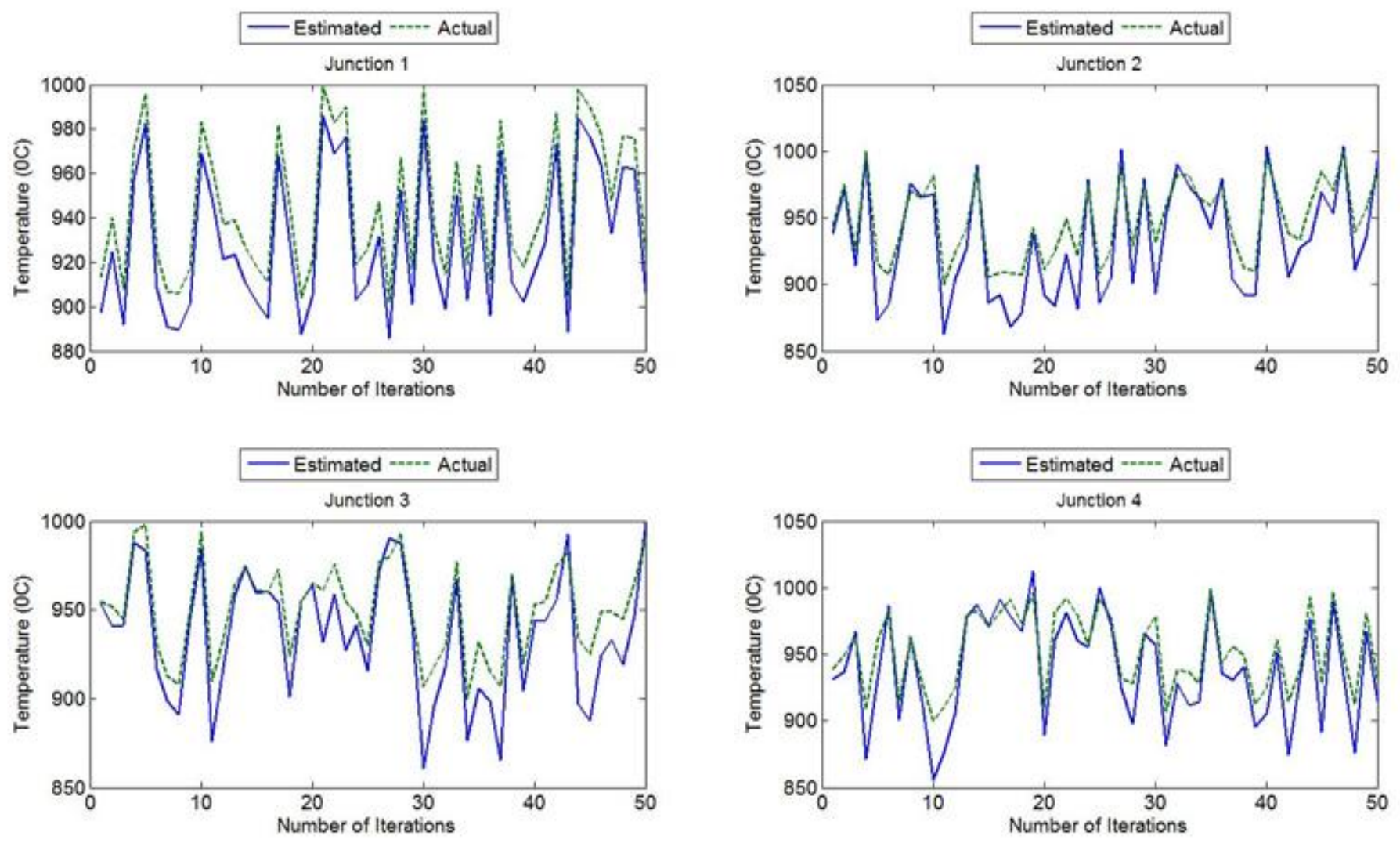

Fig 3: Range from $900^{\circ} \mathrm{C}$ to $1000^{\circ} \mathrm{C}$ - no change of Seebeck Coefficient within HAZ 

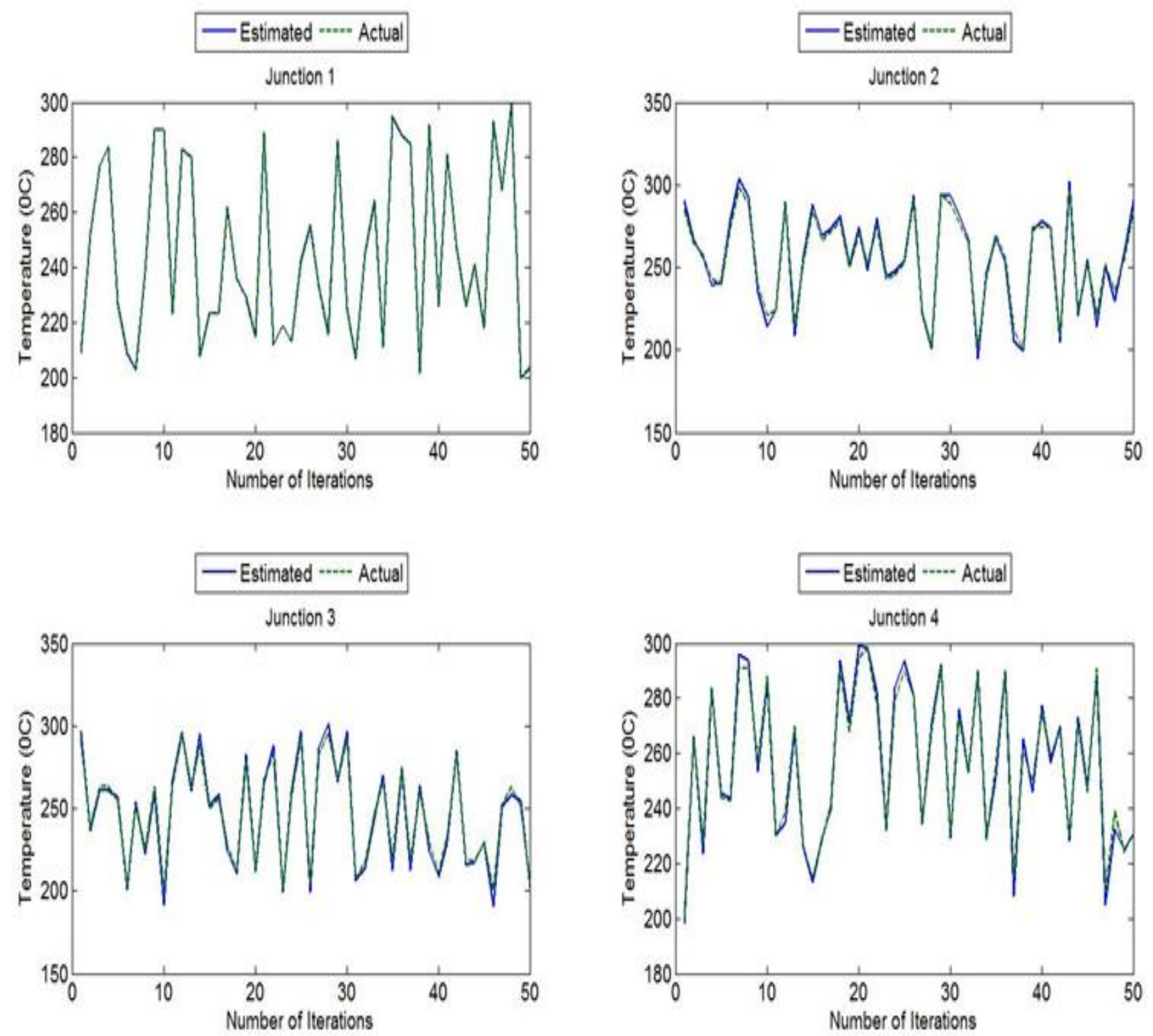

Fig 4: Range from $200^{\circ} \mathrm{C}$ to $300^{\circ} \mathrm{C}$ - no change of Seebeck Coefficient within HAZ

Simulation 2: Influence of HAZ with no temperature gradient across it

This simulation was focused on investigating the influence of changes in Seebeck coefficient in the HAZ to the accuracy of temperature measurements. The Seebeck coefficients of Chromel were increased by $25 \%$ from its normal value at each temperature and that of Alumel was decrease by $25 \%$ from its normal values at each temperature. HAZ boundaries were set to be in the same temperature as their corresponding junctions. Therefore, no temperature gradient present across any HAZs. The output of the simulation is shown in Figure 5. The estimated temperatures were in very satisfactory agreement with the corresponding actual temperatures. Further, level of accuracy in estimated temperatures was similar to that with the simulation in Fig 4. This suggests that even if the
Seebeck coefficients are significantly changed in HAZ, it does not affect the temperature measurements as long as there is no temperature gradient across HAZ. 

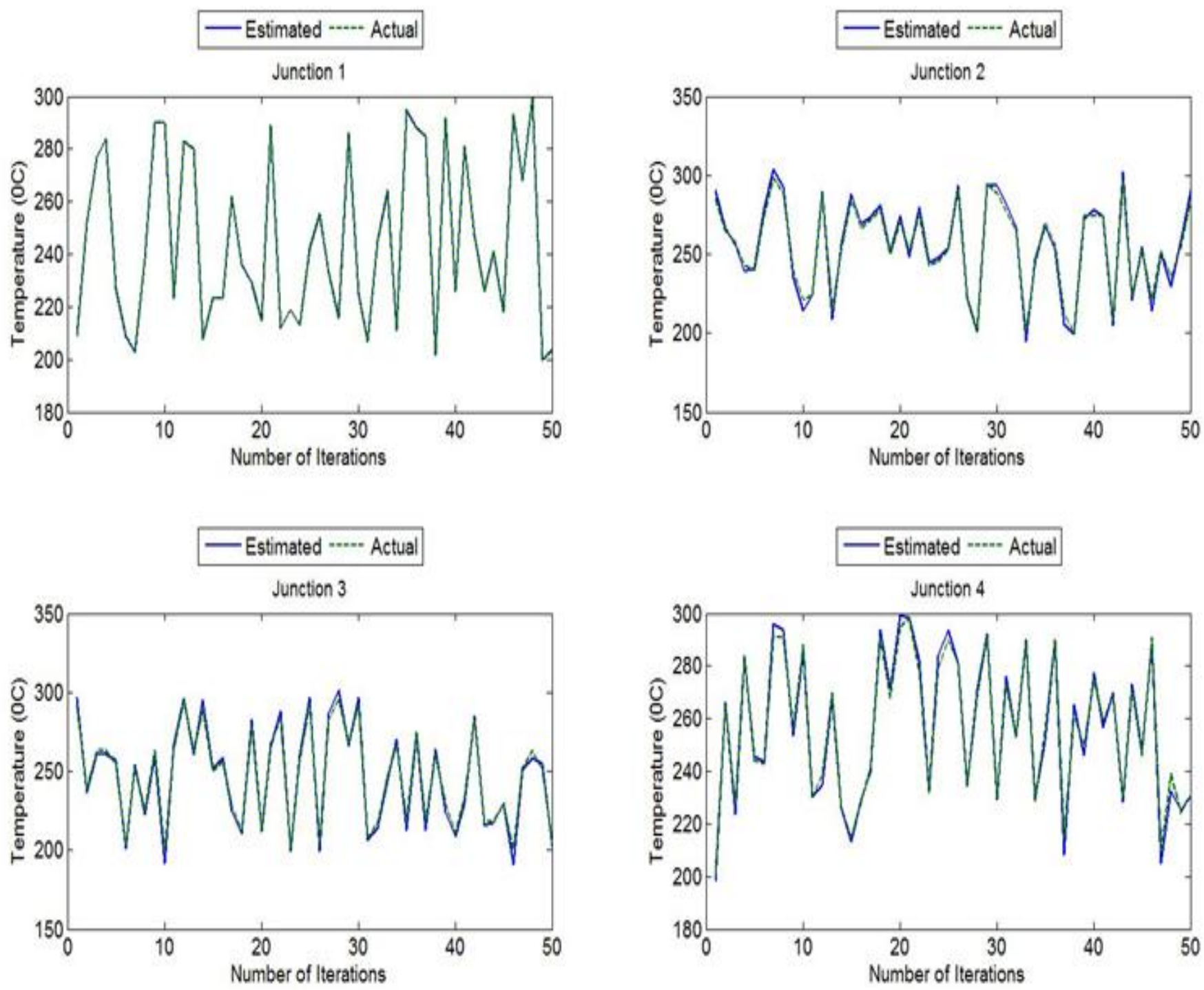

Fig 5: Range from $200^{\circ} \mathrm{C}$ to $300^{\circ} \mathrm{C}$ - Seebeck coefficient increases by $25 \%$ for Chromel and decreases by $25 \%$ for Alumel

Simulation 3: Influence of HAZ when there is a temperature gradient across it.

The effect of the change of Seebeck coefficient was investigated when there is a temperature gradient present across the HAZ. The change of Seebeck coefficient in HAZ was set similar to those in simulation 2. The boundary temperature of HAZ was set to vary randomly within a range $\pm 20 \%$ of their corresponding junction temperature. For example, the temperature $\mathrm{T}_{\mathrm{c} 1}, \mathrm{~T}_{\mathrm{c} 2}$, and $\mathrm{T}_{\mathrm{c} 3}$ is within a range $\pm 20 \%$ of $T_{c}$. The output of this simulation is shown in Figure 6. It can be seen that the estimated temperature is shifted down. This shows that change in Seebeck coefficient influence the temperature measurements where there exist temperature gradients across the HAZ. Same simulation was repeated by reducing the boundary temperature variation to $\pm 10 \%$ of corresponding junction temperature and the result is shown in Figure 7. Although still the estimated temperature is shifted down, its magnitude is much less than that with $\pm 20 \%$ variation. The magnitude of offset was not halved when the temperature range was halved. This suggests that the measured temperature is affected by the HAZ when there exist a temperature gradient across it and this effect is non-liner in nature. 

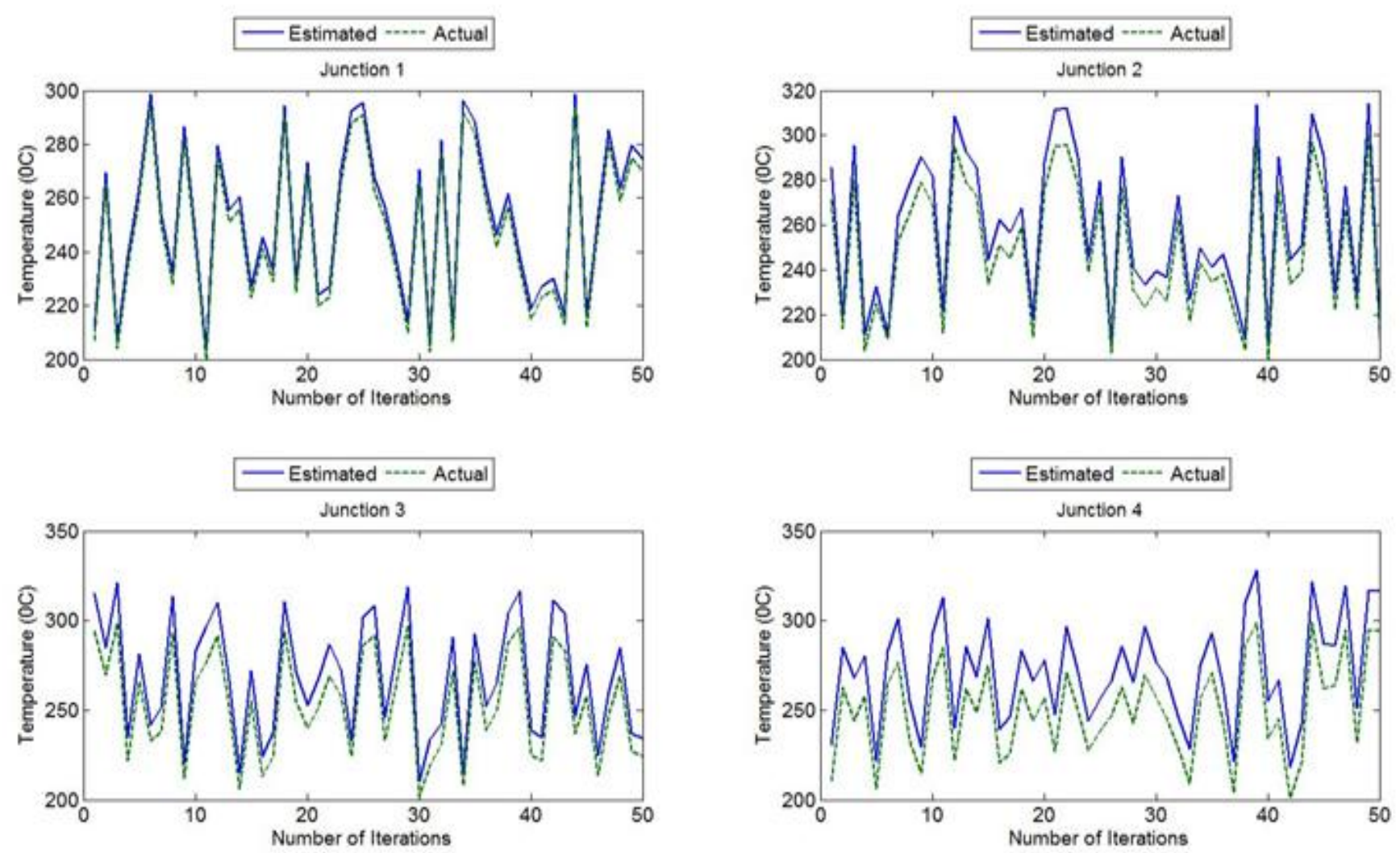

Fig 6: Range from $200^{\circ} \mathrm{C}$ to $300^{\circ} \mathrm{C}$ - Seebeck coefficient increases by $25 \%$ for Chromel and decreases by $25 \%$ for Alumel. Boundary temperature variation is $\pm 20 \%$ of the junction
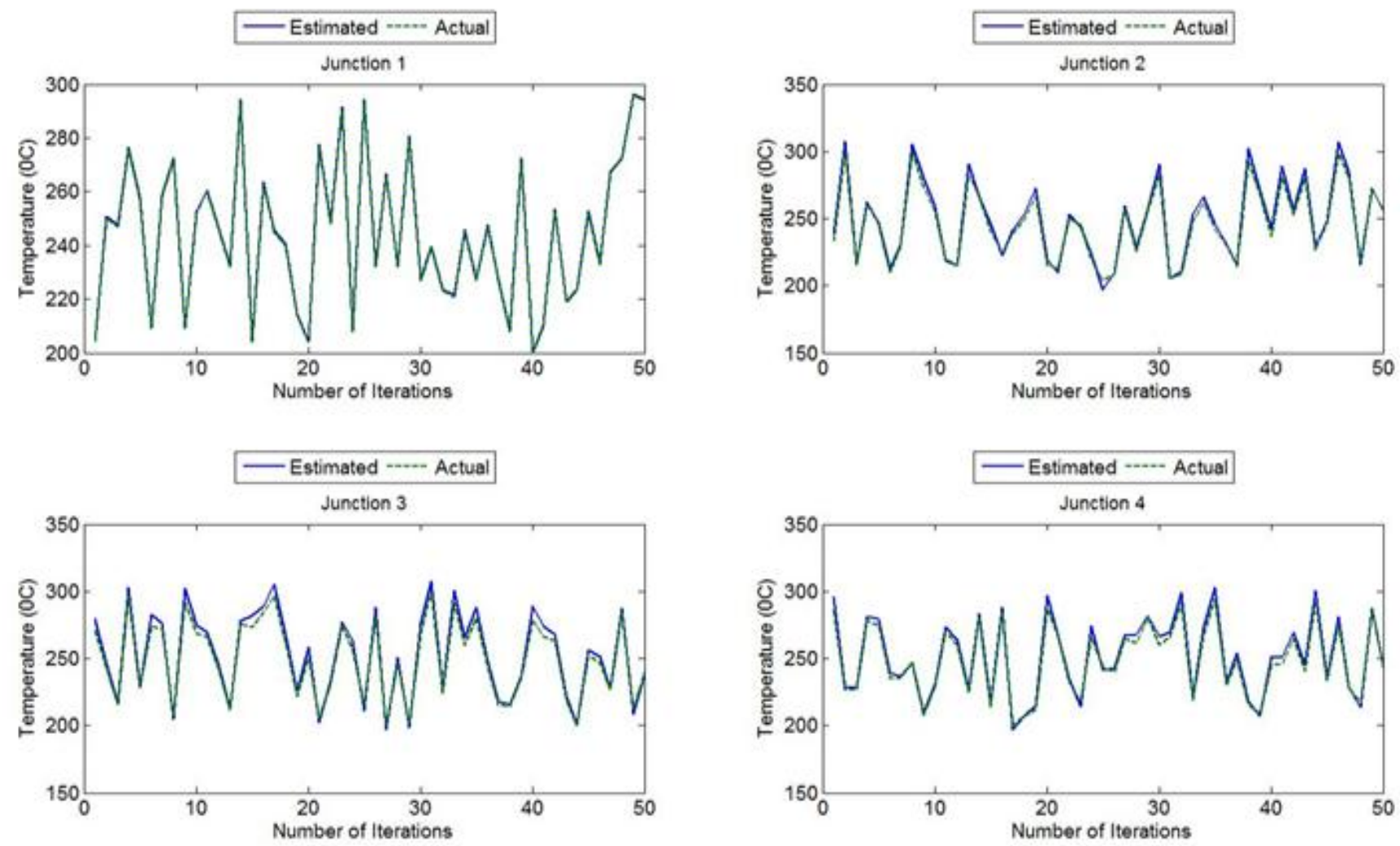

Fig 7: Range from $200^{\circ} \mathrm{C}$ to $300^{\circ} \mathrm{C}$ - Seebeck coefficient increases by $25 \%$ for Chromel and decreases by $25 \%$ for Alumel. Boundary temperature variation is $\pm 10 \%$ of the junction 


\section{CONCLUSION}

The first simulation validated the concept of multi-junction thermocouple. The method of simulation was exactly similar in all temperature ranges. Hence, the inability to accurately estimate the temperature within $900^{\circ} \mathrm{C}$ to $1000^{\circ} \mathrm{C}$ range is a not a failure of the concept. The inaccuracy of estimated Seebeck coefficients within that rage contributed to the significant deviation demonstrated. The HAZ does not influence temperature measurements as long as there is no temperature gradient across it. On the other hand, the influence that caused due to temperature gradient present across HAZ exponentially decreases when the temperature gradient decreases. In real spot welding process, size of the HAZ is very small compared with other major welding processes. Further, temperature gradient that may present across a very short distance in an operating SOFC is also very small. Hence, multi-junction thermocouple array concept cannot be expected to yield any significant problems, in terms of accuracy of measurements, when measuring the temperature of a working SOFC stack.

\section{REFERENCES}

[1] Laurencin, J., Delette, G., Morel, B., LefebvereJoud, F., and Mupeux, M. 2009, "Solid Oxide Fuel Cells damage mechanisms due to Ni-YSX reoxidation: Case of the Anode Supported Cell", Journal of Power Sources, vol. 192, no. 2, pp344352

[2] Sarantaridis, D., Rudkin, R.A., and Atkinson, A. 2008, "Oxidation failure modes of anode-supported solid oxide fuel cells", Journal of Power Sources, vol. 180, no. 2, pp704-710

[3] Faes, A., Nakajo, A., Hessler-Wyser, A., Dubois, D., Brisse, A., Modena, S., and Van herle,J. 2009, "RedOx study of anode-supported solid oxide fuel cell”, Journal of Power Sources, vol. 193, no 1. pp55-64

[4] Liu, L., Kim, G.Y., and Chandra, A. 2010, 'Modeling of thermal stresses and lifetime prediction of planar solid oxide fuel cell under thermal cycling conditions', Journal of Power Sources, vol. 195, no.8, pp 2310-2318

[5] Koeppel, B.J., Lai, K. \& Khaleel, M.A., 2011. SOFC-MP 2D User Manual, Pacific Northwest National Laboratory.

[6] Kulikovsky, A.A., 2010. "A simple equation for temperature gradient in a planar SOFC stack" , International Journal of Hydrogen Energy, vol. 35, pp308-312

[7] VanderSteen, J.D.J. \& Pharoah, J.G., 2006. "Modelling Radiation Heat Transfer With Participating Media in Solid Oxide Fuel Cells" Journal of Fuel Cell Science and Technology, vol.3, pp62.

[8] Achenbach, E., 1994. "Three-dimensional and timedependent simulation of a planar solid oxide fuel cell stack", Journal of Power Sources, vol. 49, pp333-348
Yakabe, H., T. Ogiwara, M. Hishinuma, \& I. Yasuda, 2001. "3-D model calculation for planar SOFC", Journal of Power Sources, vol.102, pp144154

[10] Nagata, S., Momma, A., Kato, T., \& Kasuga, Y., 2001. "Numerical analysis of output characteristics of tubular SOFC with internal reformer", Journal of Power Sources, vol.101, pp60-71

[11] Fischer, K. \& Seume, J.R., 2012. "Thermomechanical stress in tubular solid oxide fuel cells: Part II - Operating strategy for reduced probability of fracture failure", IET Renewable Power Generation, vol.6, pp194.

[12] Lockett, M., Simmons, M.J.H. \& Kendall, K., 2004. "CFD to predict temperature profile for scale up of micro-tubular SOFC stacks", Journal of Power Sources, vol.131, pp243-246

[13] Kakac, S., Pramuanjaroenkij, A. \& Zhou, X.Y., 2007. "A review of numerical modeling of solid oxide fuel cells", Intl. Jnl. of Hydrogen Energy, vol.32, pp761-786

[14] Marra, D., Sorrentino, M., Pianese, C., and Iwanschitz, B. 2013, 'A neural network estimator of Solid Oxide Fuel cell performance for on-field diagnostics and prognostics applications', Journal of Power Sources, vol. 241, pp 320-329

[15] Razbani, O. and Assadi, M. 2014, 'Artificial neural network model of a short stack solid oxide fuel cell based on experimental data', Journal of Power Sources, vol. 246, pp 581-586

[16] Milewski, J. and Swirski, K. 2009, 'Modelling the SOFC behaviour by artificial neural network', International journal of hydrogen energy, vol. 37, pp 5546-5553

[17] Arriagada, J., Olausson, P. and Selimovic, A. 2002, 'Artificial neural network simulator for SOFC performance prediction', Journal of Power Sources, vol. 112, pp 54-60

[18] Nakajo, A., Mueller, F., Brouwer, J., Van herle, J., and Favrat, D. 2012, "Mechanical reliability and durabiulity of SOFC stacks. Part II: Modelling of mechanical failure during ageing and cycling", Intl. Jnl. of Hydrogen Energy, vol. 37, pp9269-9286

[19] Morel, B., Roberge, R., Savoie, S., Napporn, T.W., and Meunier, M. 2007, 'An experimental evaluation of the temperature gradient in Solid Oxide Fuel Cells', Electrochemical and Solid-State Letters, vol.10, pp B31-B33

[20] Saunders, J.E.A and Davy, M.H. 2013, 'In-situ studies of gas phase composition and anode surface temperature through a model DIR-SOFC steammethane reformer at $973.15 \mathrm{~K}$, International Journal of Hydrogen Energy, vol. 38, pp 1376213773

[21] Razbani, O., Waernhus, I., and Assadi, M. 2013, "Experimental investigation of temperature distribution over a planar solid oxide fuel cell", Applied Energy, vol. 105, pp 155-160 
[22] Guan, W.B. et al., 2012. Temperature Measurement and Distribution inside Planar SOFC Stacks. Fuel Cells, vol. 12, pp24-31

[23] Bedogni, S., Campanari, S., Lora, P., Montelatici, L., and Silva, P. 2007, "Experimental analysis and modelling for a circular-planar type IT-SOFC", Journal of Power Sources", vol. 171, pp617-625

[24] Robin E. Bentley, "Theory and Practice of thermoelectric thermometry", vol.3, pp 33. 